\title{
Perceived barriers to commuter and exercise bicycling in U.S. adults: The 2017 National Household Travel Survey
}

\author{
Anna K. Porter ${ }^{a, *}$, Eleftheria Kontou ${ }^{\mathrm{b}, \mathrm{c}}$, Noreen C. McDonald ${ }^{\mathrm{b}}$, Kelly R. Evenson ${ }^{\mathrm{d}}$ \\ ${ }^{a}$ School of Health Professions, College of Nursing and Health Professions, University of Southern Mississippi, 118 College Drive \#5122, Hattiesburg, \\ MS, 39406, USA \\ ${ }^{\mathrm{b}}$ Department of City and Regional Planning, University of North Carolina at Chapel Hill, New East Building, Campus Box 3140, University of North \\ Carolina at Chapel Hill, Chapel Hill, NC, 27599-3140, USA \\ ${ }^{\mathrm{c}}$ Department of Civil and Environmental Engineering, Grainger College of Engineering, 1212 Newmark Civil Engineering Bldg, 205 N. Mathews, \\ Urbana, Illinois, 61801, USA \\ ${ }^{d}$ Department of Epidemiology, Gillings School of Global Public Health, University of North Carolina at Chapel Hill, 123 W Franklin Street, Building \\ C, Suite 410, CB 8050, Chapel Hill, NC, 27599-8050, USA
}

\section{A B S T R A C T}

Introduction: Bicycling is a type of physical activity associated with positive health outcomes, but many barriers exist to regular bicycling for recreation and transportation. The objective of this study was to describe self-reported barriers to bicycling overall, and by bicycling domain, among a national sample of persons aged 16 and above that reported bicycling outside in the past week.

Methods: This analysis, conducted in 2019, utilized data from the United States (US) Department of Transportation's 2017 National Household Travel Survey (NHTS). Weighted point estimates and 95\% confidence intervals were calculated for reported barriers to bicycling by category of bicyclist: exercise-exclusive, multi-use, and commuter.

Results: The final analytic sample was 18,189, representing approximately $7 \%$ of the US population $(\mathrm{N}=20,911,680)$. Barriers that prevented bicycling more was reported by $37.9 \%$ of the US population of adult bicyclists (95\% CI 37.2, 38.6). Barriers related to safety were more commonly reported (31.9\% of total bicyclists), compared to barriers related to infrastructure $(22.1 \%$ of total bicyclists). Safety-related barriers were more commonly reported among multi-use bicyclist (33.7\% vs. $30.9 \%$ of exercise-exclusive). Commuter bicyclists reported infrastructure barriers the least (13.9\% vs. $22.7 \%$ of exercise-exclusive). The most commonly reported single barrier to bicycling more, regardless of bicycling category, was heavy traffic (10.3\% of total bicyclists), followed by no nearby paths or trails ( $7.6 \%$ of total bicyclists). Overall, distribution of individual barriers was similar across categories of bicyclists: exercise-exclusive, multi-use, and commuter.

Conclusions: Heavy traffic and lack of separated paths or trails were the most frequently identified barriers to bicycling more. Communities wishing to promote bicycling for transportation, recreation, or both should consider how traffic reduction strategies and changes in the built environment could make bicycling safer and more accessible.

\section{Introduction}

The United States (US) Physical Activity Guidelines for Americans, 2nd edition, recommends adults engage in at least 150-300 min of moderate-intensity aerobic activity, 75-150 min of vigorous-intensity aerobic activity, or an equivalent combination per week (Physical Activity Guidelines for Americans, 2018). Bicycling, one of the most commonly reported physical activities in the US (Dai

\footnotetext{
* Corresponding author. University of Southern Mississippi, College of Nursing and Health Professions, School of Health Professions, 118 College Drive \#5122, Hattiesburg, MS, 39406, USA.

E-mail addresses: anna.k.porter@usm.edu (A.K. Porter), kontou@illinois.edu (E. Kontou), noreen@unc.edu (N.C. McDonald), kelly_evenson@ unc.edu (K.R. Evenson).
} 
et al., 2015), is one way for adults to achieve recommended levels of physical activity (Titze et al., 2014). Bicycling has also been shown to be associated with numerous health benefits (Oja et al., 2011; 2018 Physical Activity Guidelines Advisory Committee, 2018).

In $2012,21 \%$ of the US adult population reported riding a bicycle in the past 30 days for any purpose; $13 \%$ rode a bicycle for recreation and $8 \%$ rode for transportation (Porter et al., 2018b). However, bicycling mode share for commuting to and from work is substantially lower. According to data from the National Household Travel Survey (NHTS) (Federal Highway Administration, 2017), in 2017 the share of commuter bicycling on any given day for workers was 1.1\%, rising from 0.6\% in 2009 (Pucher et al., 2011). The prevalence of bicycling for transportation in the US is substantially lower than European countries. One study reported that $48 \%$ of the population residing in 5 regions across Europe bicycled for transportation in the past week (Mertens et al., 2017). Barriers that prevent US residents from bicycling for recreation and transportation likely contribute to these geographic differences (Pucher and Buehler, 2016).

Understanding barriers to bicycling in the US is critical. Identification of bicycling barriers can assist policymakers, city planners, and transportation and public health agencies for designing community-level approaches to increase bicycling behavior (Community Preventive Sercies Task Force, 2016). Understanding barriers could also help in the design of interventions to increase bicycling mode shares. For example, both educational endeavors and good infrastructure design practices, which enhance connectivity and mixed land use, can reduce active transportation barriers (Handy et al., 2002). Workplace programs promoting commuting by bicycle contribute to greater commuting bicycle shares (Porter et al., 2019b). Car-restrictive policies lead to lower speeds and, thus, decreasing automobile use attractiveness and setting better conditions for bicycling (Pucher et al., 2010).

Bikeability, as defined by Whalgren \& Schantz (2011), is concerned with environmental factors associated with bicycling, and the interaction of these factors with the bicycle and the bicyclist for a given trip. Prior research has identified major environmental obstacles to bicycle riding, including safety issues primarily due to car traffic, bicycle lanes density and accessibility, lack of protected infrastructure, and aspects of the natural environment such as weather and topography (Cervero and Duncan, 2003; Fowler et al., 2017). Further, bikeability of an environment is tied to pereceptions of the environment, such as safety, comfort, weather conditions, and security (Moudon and Lee, 2003; Nahal and Mitra, 2018). There is also research that has identified differing environmental factors hindering domain specific bicycling - transportation (e.g., going to the store, visiting someone, or commuting to work/school) and recreation (e.g., exercise or for fun). Recreation and transportation bicyclists are encouraged by conducive infrastructure, while bicycling comfort and car-limiting behaviors are primarily associated with transportation bicycling (Xing et al., 2010).

Exploration of perceived barriers by bicycling domain is limited. It is possible that perceived bicycling barriers differ by bicycling domain, due to where, how, and for what purpose individuals are bicycling. In addition, bicycling barriers have not yet been examined in the US at a national level. The objective of this study was to describe self-reported barriers to bicycling overall, and by bicycling domain, among a national sample of persons aged 16 and above that reported bicycling outside in the past week.

\section{Methods}

\subsection{Study sample}

Data are from the US Department of Transportation's 2017 National Household Travel Survey (NHTS) (Federal Highway Administration, 2017). The 2017 NHTS is the eighth iteration of a nationally representative cross-sectional survey on daily travel, which occurs at irregular intervals. Data were collected from stratified random samples of US households. Address based sampling was utilized, in which a random selection of residential addresses was identified via the US Postal Service (Federal Highway Administration, 2018). Participants completed the 2017 NHTS via two phases - (1) a mail-based household recruitment survey, which collected information about the household, transportation, and travel behavior, and (2) a primarily web-based person-level retrieval survey, which inquired about travel conducted on a study-assigned day (Federal Highway Administration, 2018). More information on the NHTS and questionnaires used can be found at nhts.ornl.gov. The University of Southern Mississippi Institutional Review Board deemed this study exempt from review.

\subsection{Measures}

As part of the 2017 NHTS retrieval survey, participants were asked how many times they rode a bicycle outside including bicycling to exercise or to get somewhere in the past week. If an individual bicycled in the past week, indicated by a value greater than 0 , they were asked how many of these bicycle rides were strictly to exercise. For this analysis, participants were categorized into two mutually exclusive groups. Participants who indicated that all of their bicycle rides were for exercise (i.e., total number of rides equal to the number of exercise rides) were categorized as an "exercise-exclusive bicyclist"; otherwise, participants were categorized as a "multiuse bicyclist". The 2017 NHTS also assessed the usual travel mode for getting to work in the last week for employed individuals working outside home. Twenty modes were offered as travel options (e.g., car, bicycle, walking, but, taxi, etc.). Employed participants that worked outside the home and indicated that they reached their primary job via bicycle were categorized as "commuter bicyclists". This group was not mutually exclusive from the "multi-use bicyclists". If a participant reported that all of their rides were for exercise but also reported bicycling to work, they were categorized as a "multi-use bicyclist".

In the 2017 NHTS, participants aged 16 and above who reported riding a bicycle in the past week were asked to report reasons they did not bike more. These reasons fell into two areas: infrastructure (no nearby paths or trails, no sidewalks or sidewalks are in poor condition, no nearby parks) and safety (street crossings are unsafe, heavy traffic with too many cars, not enough lighting at night). Participants selected all that applied, which resulted in 7 categories for infrastructure barriers ( 3 individual barriers and their 4 
combinations) and 7 categories for safety barriers ( 3 individual barriers and their 4 combinations). Sociodemographic characteristics of participants, including age, gender, race/ethnicity, educational attainment, household income, and count of household vehicles were also collected.

\subsection{Statistical analysis}

Participants were excluded from the final analytic sample if they were under the age of 16, reported not riding a bicycle in the past week, or had missing data. Weighted descriptive characteristics were calculated for the proportion of participants who reported riding a bicycle in the past week (total, exercise-exclusive, multi-use, commuter) by age, gender, race/ethnicity, educational attainment, household income, and count of household vehicles. Weighted point estimates and 95\% confidence intervals were calculated for reported barriers to bicycling more by category of bicyclist: exercise-exclusive, multi-use, and commuter. Analyses were conducted in 2019 using Python 2.7.3.

\section{Results}

In total, 264,234 individuals completed the survey. After excluding participants younger than 16 years of age ( $\mathrm{n}=27,939)$, those who did not ride a bicycle in the past week $(n=217,633)$ and those with missing data $(n=473)$, the final analytic sample was 18,189 , representing approximately $7 \%$ of the US population $(\mathrm{N}=20,911,680)$. Of the total population of bicyclists, $63.6 \%$ were exerciseexclusive and $36.4 \%$ were multi-use. Approximately $7 \%$ of those categorized as multi-use bicyclists identified as a bicycle commuter, representing $0.4 \%$ of the US population. Descriptive characteristics of the sample are reported in Table 1.

Reasons for not bicycling more, by type of bicyclist, are reported in Table 2 . The majority of bicyclists did not report any barriers to bicycling more $(62.1 \%$ of total bicyclists). Barriers related to safety were more commonly reported (31.9\% of total bicyclists), as

Table 1

Weighted descriptive characteristics of study sample, 2017 National Household Travel Survey $(n=18,189 ; N=20,911,680)$.

\begin{tabular}{|c|c|c|c|c|}
\hline & Total Bicyclists & Exercise-Exclusive Bicyclists & Multi-use Bicyclists & Commuter Bicyclists $^{\mathrm{a}}$ \\
\hline & $\mathrm{n}=18,189$ & $\mathrm{n}=11,563$ & $\mathrm{n}=6626$ & $\mathrm{n}=1053$ \\
\hline & $\mathrm{N}=20,911,680$ & $\mathrm{~N}=12,070,238$ & $\mathrm{~N}=8,841,442$ & $\mathrm{~N}=1,425,296$ \\
\hline Age [mean (SD)] & $42.38(16.09)$ & $45.34(16.09)$ & $38.33(15.16)$ & $37.18(12.8)$ \\
\hline \multicolumn{5}{|l|}{ Gender [n (\%)] } \\
\hline Male & $11,177(62.9)$ & $6999(61.0)$ & $4178(65.5)$ & $749(74.6)$ \\
\hline Female & $7012(37.1)$ & $4564(39.0)$ & 2448 (34.5) & $304(25.4)$ \\
\hline \multicolumn{5}{|l|}{ Race $[\mathrm{n}(\%)]$} \\
\hline White & $15,331(76.7)$ & $9863(77.6)$ & $5468(75.5)$ & $891(81.2)$ \\
\hline Black or African American & $945(10.3)$ & $583(10.1)$ & $362(10.6)$ & $31(4.3)$ \\
\hline Asian & $763(4.9)$ & $452(4.8)$ & $311(5.1)$ & $59(6.8)$ \\
\hline Other $^{\mathrm{b}}$ & $1150(8.1)$ & $665(7.6)$ & $485(8.8)$ & $72(7.8)$ \\
\hline \multicolumn{5}{|l|}{ Hispanic or Latino Origin [n (\%)] } \\
\hline Yes & $1406(14.4)$ & $888(15.1)$ & $518(13.3)$ & $72(10.9)$ \\
\hline No & $16,783(85.6)$ & $10,675(84.9)$ & $6108(86.7)$ & $981(89.1)$ \\
\hline \multicolumn{5}{|l|}{ Educational Attainment [n (\%)] } \\
\hline Less than HS & $939(8.7)$ & $443(7.0)$ & $496(11.0)$ & $32(5.9)$ \\
\hline HS graduate or GED & $2229(15.2)$ & $1421(15.6)$ & $808(14.6)$ & $101(7.2)$ \\
\hline Some college or associates degree & $4377(24.8)$ & $2993(26.6)$ & 1384 (22.5) & $182(23.3)$ \\
\hline Bachelor's degree & $5222(26.2)$ & $3383(27.3)$ & $1839(24.8)$ & $282(23.3)$ \\
\hline Graduate or professional degree & $5422(25.1)$ & $3323(23.6)$ & 2099 (27.2) & $456(40.3)$ \\
\hline \multicolumn{5}{|l|}{ Household Income [n (\%)] } \\
\hline Less than $\$ 25,000$ & $2318(17.7)$ & 1165 (14.6) & $1153(21.9)$ & $142(16.1)$ \\
\hline$\$ 25,000-\$ 49,999$ & $2731(17.1)$ & $1723(16.0)$ & $1008(18.6)$ & $166(21.9)$ \\
\hline$\$ 50,000-\$ 99,999$ & $5489(28.1)$ & $3641(30.4)$ & $1848(25.0)$ & $308(27.6)$ \\
\hline$\$ 100,000$ or more & $7263(35.3)$ & $4760(36.9)$ & $2503(33.1)$ & $421(34.1)$ \\
\hline Don't know/refused & $388(1.9)$ & $274(2.2)$ & $114(1.5)$ & $16(0.4)$ \\
\hline \multicolumn{5}{|l|}{ Count of household vehicles [n (\%)] } \\
\hline 0 & $859(9.5)$ & 225 (4.5) & $634(16.4)$ & $134(21.9)$ \\
\hline 1 & $3796(25.7)$ & $2036(22.3)$ & $1760(30.3)$ & $380(44.0)$ \\
\hline 2 & $7725(34.3)$ & $5184(36.3)$ & 2541 (31.4) & $348(21.6)$ \\
\hline 3 & 3601 (17.6) & $2538(20.8)$ & $1063(13.3)$ & $119(7.6)$ \\
\hline 4 & $1408(8.8)$ & $1004(11.0)$ & $404(5.9)$ & $47(3.9)$ \\
\hline 5 or more & $800(4.1)$ & $576(5.1)$ & $224(2.8)$ & $25(1.0)$ \\
\hline \multicolumn{5}{|l|}{ Household built environment [n (\%)] } \\
\hline Urban & $15,040(82.7)$ & $9253(84.2)$ & 5787 (91.5) & 1007 (95.7) \\
\hline Rural & 3149 (17.3) & $2310(15.8)$ & $839(8.5)$ & $46(4.3)$ \\
\hline
\end{tabular}

${ }^{\text {a }}$ Not mutually exclusive from the multi-use bicyclists; employed participants that did not work from home and indicated that they reached their primary job via bicycle.

b Includes American Indian or Alaska Native, Native Hawaiian or other Pacific Islander, Multiple responses, and some other race. 
compared barriers related to infrastructure $(22.1 \%$ of total bicyclists). Safety-related barriers were more commonly reported among multi-use bicyclist (33.7\% vs. $30.9 \%$ of exercise-exclusive). Commuter bicyclists reported infrastructure barriers the least (13.9\% vs. $22.7 \%$ of exercise-exclusive). The most commonly reported single barrier to bicycling more, regardless of bicycling category, was heavy traffic with too many cars (10.3\% of total bicyclists), followed by no nearby paths or trails (7.6\% of total bicyclists). Overall, distribution of individual barriers was similar across categories of bicyclists.

\section{Discussion}

Perceived infrastructure and/or safety barriers inhibit bicycling for approximately $38 \%$ of the US population of adult bicyclists. Commuters were the least likely to report bicycling barriers; this could be due to their personal experiences and perceptions, or it could be that they are more likely to be bicycling in environments that are conducive to the behavior. Safety related barriers were overall more commonly reported as preventing bicyclists from riding more, as compared to infrastructure related barriers. Certain types of infrastructure, such as lane width and exclusive bicycle lanes, are directly associated with bicycling safety (Morrison et al., 2019; Raihan et al., 2019). In this population, the most commonly reported barriers were heavy traffic and no nearby paths. This uncovers needs for traffic calming measures (Brown et al., 2017), dynamic signal control (Abu-Lebdeh and Benekohal, 2003), and policy interventions (Krizek et al., 2009). It also suggests the need for greater bicycling infrastructure accessibility, separation from main road arteries, and car-restricting policies to encourage more frequent bicycle use. Conceivably, if paths were available that allowed for complete separation from cars for the entirety of a bicycle ride, both barriers could be addressed (Brown et al., 2017; Hine and Russell, 1993). One consideration with paths is the ability of both transportation and recreation bicyclists to benefit from them, by assuring that they provide access to popular destinations and for recreation activities.

This study examined perceived barriers to safety and infrastructure, rather than GIS-based objective measures. Perceptions of safety and infrastructure are largely influenced by and associated with the objective environment but can also be influenced by other individual factors such as gender, age, and experience bicycling (Ma and Dill, 2017; Xing et al., 2010). Both perceived and objective measures have been shown to influence bicycling behavior (Ma and Dill, 2017; Porter et al., 2019a; Porter et al., 2018a), and this association differs depending on the domain or purpose of bicycling. Ma and Dill (2017) found that utilitarian bicyclists were more influenced by both the objective and perceived environment, while recreation riders were more influenced by their perceptions of the

Table 2

Reasons for not bicycling more, by type of bicyclist (weighted); 2017 National Household Travel Survey ( $\mathrm{n}=18,189 ; \mathrm{N}=20,911,680$ ).

\begin{tabular}{|c|c|c|c|c|}
\hline & $\begin{array}{l}\text { Total } \\
\text { Bicyclists }\end{array}$ & $\begin{array}{l}\text { Exercise-Exclusive } \\
\text { Bicyclists }\end{array}$ & $\begin{array}{l}\text { Multi-use } \\
\text { Bicyclists }\end{array}$ & $\begin{array}{l}\text { Commuter } \\
\text { Bicyclists }^{\mathrm{a}}\end{array}$ \\
\hline \multicolumn{5}{|l|}{ Infrastructure $[\%(95 \% \mathrm{CI})]$} \\
\hline No nearby paths or trails & $7.6(7.2,8.0)$ & $7.4(7.0,7.9)$ & $7.9(7.2,8.5)$ & $7.5(6.1,9.3)$ \\
\hline No sidewalks or sidewalks are in poor condition & $4.3(4.0,4.6)$ & $4.1(3.8,4.5)$ & $4.7(4.2,5.2)$ & $2.9(2.0,4.0)$ \\
\hline No nearby parks & $0.8(0.7,0.9)$ & $0.7(0.6,0.9)$ & $0.8(0.6,1.1)$ & $0.3(0.1,0.8)$ \\
\hline $\begin{array}{l}\text { No nearby paths or trails and no sidewalks or sidewalks are in poor } \\
\text { condition }\end{array}$ & $3.0(2.8,3.3)$ & $3.1(2.8,3.4)$ & $3.1(2.7,3.5)$ & $1.9(1.2,2.9)$ \\
\hline No nearby paths or trails and no nearby parks & $2.0(1.8,2.2)$ & $2.2(2.0,2.5)$ & $1.6(1.4,2.0)$ & $0.9(0.5,1.6)$ \\
\hline No sidewalks or sidewalks are in poor condition and no nearby parks & $0.4(0.3,0.5)$ & $0.4(0.3,0.5)$ & $0.3(0.2,0.5)$ & $0.1(0.0,0.5)$ \\
\hline $\begin{array}{l}\text { No nearby paths or trails, no sidewalks or sidewalks are in poor } \\
\text { condition, and no nearby parks }\end{array}$ & $4.0(3.7,4.3)$ & $4.7(4.4,5.1)$ & $2.8(2.4,3.2)$ & $0.5(0.2,1.1)$ \\
\hline None reported & $\begin{array}{l}77.9(76.6, \\
79.1)\end{array}$ & $77.3(75.7,78.8)$ & $\begin{array}{l}78.9(76.8 \\
80.9)\end{array}$ & $86.0(81.0,91.2)$ \\
\hline \multicolumn{5}{|l|}{ Safety $[\%(95 \% \mathrm{CI})]$} \\
\hline Street crossings are unsafe & $1.5(1.3,1.7)$ & $1.3(1.1,1.5)$ & $2.0(1.6,2.3)$ & $1.5(0.9,2.5)$ \\
\hline Heavy traffic with too many cars & $\begin{array}{l}10.3(9.9 \\
10.8)\end{array}$ & $10.0(9.5,10.6)$ & $\begin{array}{l}10.9(10.2 \\
11.7)\end{array}$ & $11.6(9.8,13.7)$ \\
\hline Not enough lighting at night & $4.9(4.6,5.2)$ & $5.2(4.8,5.6)$ & $4.4(4.0,5.0)$ & $3.5(2.6,4.8)$ \\
\hline Street crossings are unsafe and heavy traffic with too many cars & $6.2(5.9,6.6)$ & $5.5(5.1,5.9)$ & $7.5(6.9,8.2)$ & $8.3(6.8,10.1)$ \\
\hline Street crossings are unsafe and not enough lighting at night & $1.0(0.8,1.1)$ & $0.9(0.8,1.1)$ & $1.0(0.8,1.3)$ & $0.6(0.3,1.2)$ \\
\hline Heavy traffic with too many cars and not enough lighting at night & $3.3(3.1,3.6)$ & $3.3(3.0,3.7)$ & $3.3(2.9,3.8)$ & $2.8(1.9,3.9)$ \\
\hline $\begin{array}{l}\text { Street crossings are unsafe, heavy traffic with too many cars, and not } \\
\text { enough lighting at night }\end{array}$ & $4.6(4.3,4.9)$ & $4.6(4.2,5.0)$ & $4.7(4.2,5.2)$ & $3.8(2.8,5.1)$ \\
\hline None reported & $\begin{array}{l}68.1(66.9 \\
69.4)\end{array}$ & $69.2(68.5,70.8)$ & $\begin{array}{l}66.3(64.1 \\
68.3)\end{array}$ & $68.0(62.8,73.4)$ \\
\hline \multicolumn{5}{|l|}{ Barriers to bicycling (composite measure) $[\%(95 \% \mathrm{CI})]$} \\
\hline Infrastructure & $\begin{array}{l}22.1(21.5 \\
22.7)\end{array}$ & $22.7(22.0,23.5)$ & $\begin{array}{l}21.1(20.1 \\
22.1)\end{array}$ & $14.0(12.0,16.2)$ \\
\hline Safety & $\begin{array}{l}31.9(31.2, \\
32.6)\end{array}$ & $30.9(30.0,31.7)$ & $\begin{array}{l}33.7(32.6, \\
34.9)\end{array}$ & $32.0(29.3,34.9)$ \\
\hline Infrastructure and safety & $\begin{array}{l}16.1(15.6, \\
16.7)\end{array}$ & $16.4(15.8,17.1)$ & $\begin{array}{l}15.6(14.8, \\
16.5)\end{array}$ & $11.0(9.3,13.1)$ \\
\hline No reported barriers & $\begin{array}{l}62.1(61.4 \\
62.8)\end{array}$ & $62.9(62.0,63.7)$ & $\begin{array}{l}60.8(59.6 \\
61.9)\end{array}$ & $65.1(62.1,67.9)$ \\
\hline
\end{tabular}

${ }^{a}$ Not mutually exclusive from the multi-use bicyclists; employed participants that did not work from home and indicated that they reached their primary job via bicycle. 
environment. This may help explain the findings in this study.

\subsection{Limitations}

The infrastructure queried in the 2017 NHTS was not specific to bicycling - the same questions were asked for both walking and bicycling. This could in part explain why infrastructure barriers were less commonly reported; bicyclists may not consider lack of access to sidewalks and parks as prohibitive of bicycling, for example, but other more bicycle-specific infrastructure such as bicycle lanes and traffic calming may be more relevant to bicycling frequency. These data represent US adults who rode a bicycle in the past week. Results may differ for individuals who ride a bicycle less frequently, or do not ride a bicycle at all. Frequency of bicycling within the past week was not examined in this study, which may have confounded the findings. Frequency of bicycling was not available for commuter bicyclists. Further, information on bicycling experience, such as how many years a person has been bicycling for a particular purpose, was not assessed and may have also confounded the findings. More experienced bicyclists may perceive or identify different barriers from those with less experience (Manaugh et al., 2017).

\subsection{Future work}

To address these limitations, we propose actions that would help researchers and practitioners assess barriers to bicycling across different domains, for both those who are bicyclists and those who are not. We specifically propose that in future iterations of the NHTS survey, questions are designed that specifically assess barriers to bicycling separate from barriers to walking. We further suggest that bicycling barriers are asked to both those who rode a bicycle in the past week and those who did not. A more representative population would enable assessment of bicycling obstacles, including safety and infrastructure concerns, across bicyclists and other mode users while also enabling comparisons across bicycling domains.

\section{Conclusions}

Heavy traffic and lack of separated paths were the most frequently identified barriers to bicycling more. This assessment did not identify substantial differences in the perceived obstacles that exercise, multi-use, and commuter bicyclists face, suggesting that recreational and transportation bicycling differences might be associated with other aspects, such as personal health, socio-economic, and environmental factors (Xing et al., 2010). Communities wishing to promote bicycling for transportation, recreation, or both, should consider how changes in the built environment could make bicycling safer. Transportation interventions and policies that aim to reduce car traffic have the potential to promote bicycling physical activity for US adults.

\section{CRediT authorship contribution statement}

Anna K. Porter: Conceptualization, Formal analysis, Writing - original draft, Writing - review \& editing. Eleftheria Kontou: Software, Formal analysis, Writing - original draft, Writing - review \& editing. Noreen C. McDonald: Writing - review \& editing. Kelly R. Evenson: Supervision, Writing - review \& editing.

\section{Acknowledgements}

EK and NM received funding from the US Department of Transportation through the Southeastern Transportation Research, Innovation, Development and Education Center, the UTC for the southeastern region.

All authors contributed to the study conception, writing, data interpretation, and critical review of the manuscript. AKP drafted the manuscript. EK conducted the analyses.

No financial disclosures were reported by the authors of this paper.

\section{References}

2018 Physical Activity Guidelines Advisory Committee, 2018. Physical Activity Guidelines Advisory Committee Scientific Report. U.S. Department of Health and Human Services, Washington, DC, 2018.

Abu-Lebdeh, G., Benekohal, R.F., 2003. Design and evaluation of dynamic traffic management strategies for congested conditions. Transp. Res. A Policy Pract. 37 (2), 109-127.

Brown, V., Moodie, M., Carter, R., 2017. Evidence for associations between traffic calming and safety and active transport or obesity: a scoping review. Journal of Transport \& Health 7, 23-37.

Cervero, R., Duncan, M., 2003. Walking, bicycling, and urban landscapes: evidence from the san francisco bay area. Am. J. Public Health 93 (9), 1478-1483. https:// doi.org/10.2105/ajph.93.9.1478.

Community Preventive Sercies Task Force, 2016. Physical Activity: Built Environment Approaches Combining Transportation System Interventions with Land Use and Environmental Design. Retrieved from. https://www.thecommunityguide.org/sites/default/files/assets/PA-Built-Environments.pdf.

Dai, S., Carroll, D.D., Watson, K.B., Paul, P., Carlson, S.A., Fulton, J.E., 2015. Participation in types of physical activities among US adults-national health and nutrition examination survey 1999-2006. J. Phys. Act. Health 12 (1), S128-S140. https://doi.org/10.1123/jpah.2015-0038.

Fowler, S.L., Berrigan, D., Pollack, K.M., 2017. Perceived barriers to bicycling in an urban U.S. environment. J Transp Health 6, 474-480. https://doi.org/10.1016/j. jth.2017.04.003.

Handy, S.L., Boarnet, M.G., Ewing, R., Killingsworth, R.E., 2002. How the built environment affects physical activity: views from urban planning. Am. J. Prev. Med. 23 (2 Suppl. 1), 64-73.

Highway Administration, Federal, 2017. National Household Travel Survey, p. 2017. Retrieved from: https://nhts.ornl.gov/. 
Highway Administration, Federal, 2018. 2017 NHTS Data User Guide. Washington, D.C.

Hine, J., Russell, J., 1993. Traffic barriers and pedestrian crossing behaviour. J. Transp. Geogr. 1 (4), 230-239. https://doi.org/10.1068/b34023.

Krizek, K.J., Handy, S.L., Forsyth, A., 2009. Explaining changes in walking and bicycling behavior: challenges for transportation research. Environ. Plan. Plan. Des. 36 (4), 725-740.

Ma, L., Dill, J., 2017. Do people's perceptions of neighborhood bikeability match reality? Journal of Transport and Land Use 10 (1), 291-308. https://doi.org/ 10.5198/jtlu.2015.796.

Manaugh, K., Boisjoly, G., El-Geneidy, A., 2017. Overcoming barriers to cycling: understanding frequency of cyclign in a University setting and the factors preventing commuters from cycling on a regular basis. Transportation 44 (4), 871-884. https://doi.org/10.1007/s11116-016-9682-x.

Mertens, L., Compernolle, S., Deforche, B., Mackenbach, J.D., Lakerveld, J., Brug, J., Van Dyck, D., 2017. Built environmental correlates of cycling for transport across Europe. Health Place 44, 35-42. https://doi.org/10.1016/j.healthplace.2017.01.007.

Morrison, C.N., Thompson, J., Kondo, M.C., Beck, B., 2019. On-road bicycle lane types, roadway characteristics, and risks for bicycle crashes. Accid. Anal. Prev. 123, 123-131. https://doi.org/10.1016/j.aap.2018.11.017.

Moudon, A.V., Lee, C., 2003. Walking and bicycling: an evaluation of environmental audit instruments. Am. J. Health Promot. 18 (1), 21-37. https://doi.org/ 10.4278/0890-1171-18.1.21.

Nahal, T., Mitra, R., 2018. Facilitators and barriers to winter cycling: case study of a downtown university in Toronto, Canada. J Transp Health 10, 262-271. https:// doi.org/10.1016/j.jth.2018.05.012.

Oja, P., Titze, S., Bauman, A., de Geus, B., Krenn, P., Reger-Nash, B., Kohlberger, T., 2011. Health benefits of cycling: a systematic review. Scand. J. Med. Sci. Sport. 21 (4), 496-509. https://doi.org/10.1111/j.1600-0838.2011.01299.x.

Physical Activity Guidelines for Americans, 2018. Washington, D.C.: US Department of Health and Human Services.

Porter, A.K., Kohl, H.W., Pérez, A., Reininger, B., Pettee Gabriel, K., Salvo, D., 2018a. Perceived social and built environment correlates of transportation and recreation-only bicycling among adults. Prev. Chronic Dis. 15, E135. https://doi.org/10.5888/pcd15.180060.

Porter, A.K., Salvo, D., Pérez, A., Reininger, B., Kohl, H.W., 2018b. Intrapersonal and environmental correlates of bicycling in U.S. Adults. Am. J. Prev. Med. 54 (3), 413-418. https://doi.org/10.1016/j.amepre.2017.10.008.

Porter, A.K., Kohl, H.W., Perez, A., Reininger, B., Pette Gabriel, K., Salvo, D., 2019a. Bikeability: assessing the objectively measured environment in relation to recreation and transportation bicycling. Environ. Behav. https://doi.org/10.1177/0013916518825289.

Porter, A.K., Kohl, H.W., Salvo, D., 2019b. Dose-response association of workplace facilities and policies with commuter bicycling among adults. J Transp Health 14. https://doi.org/10.1016/j.jth.2019.100603.

Pucher, J., Buehler, R., 2016. Safer cycling through improved infrastructure. Am. J. Public Health 106 (12), 2089-2091. https://doi.org/10.2105/ AJPH.2016.303507.

Pucher, J., Dill, J., Handy, S., 2010. Infrastructure, programs, and policies to increase bicycling: an international review. Prev. Med. 50 (Suppl. 1), S106-S125. https:// doi.org/10.1016/j.ypmed.2009.07.028.

Pucher, J., Buehler, R., Merom, D., Bauman, A., 2011. Walking and cycling in the United States, 2001-2009: evidence from the national household travel surveys. Am. J. Public Health 101 (Suppl. 1), S310-S317. https://doi.org/10.2105/AJPH.2010.300067.

Raihan, M.A., Alluri, P., Wu, W., Gan, A., 2019. Estimation of bicycle crash modification factors (CMFs) on urban facilities using zero inflated negative binomial models. Accid. Anal. Prev. 123, 303-313. https://doi.org/10.1016/j.aap.2018.12.009.

Titze, S., Merom, D., Rissel, C., Bauman, A., 2014. Epidemiology of cycling for exercise, recreation or sport in Australia and its contribution to health-enhancing physical activity. J. Sci. Med. Sport 17 (5), 485-490. https://doi.org/10.1016/j.jsams.2013.09.008.

Wahlgren, L., Schantz, P., 2011. Bikeability and methodological issues using the active commuting route environment scale (ACRES) in a metropolitan setting. BMC Med. Res. Methodol. 11 (1), 6. https://doi.org/10.1186/1471-2288-11-6.

Xing, Y., Handy, S.L., Mokhtarian, P.L., 2010. Factors associated with proportions and miles of bicycling for transportation and recreation in six small US cities. Transp. Res. D Transp. Environ. 15 (2), 73-81. https://doi.org/10.1016/j.trd.2009.09.004. 